\title{
Discriminated and nondiscriminated avoidance conditioning of the rearing response in rats
}

\author{
AKIRA SHISHIMI and HIROSHI IMADA \\ Kwansei Gakuin University, Uegahara, Nishinomiya, Japan 662
}

\begin{abstract}
Experiment 1 employed a shock box in which light beams ran at $10,15,20$, or $25 \mathrm{~cm}$ above the floor level of the box. Four groups of nine rats each were trained to avoid shock by cutting the light beams or letting them pass by, which the animal accomplished by upward or downward change of its posture. Training employed a discriminated avoidance paradigm, 60 trials per day for 5 days, with a 5 -sec CS-US interval. Acquisition of the rearing avoidance response was observed only in the 15-cm condition. Using the same apparatus as in Experiment 1 and with a beam height of $15 \mathrm{~cm}$, the rearing avoidance response was successfully conditioned in five rats using a nondiscriminated avoidance conditioning paradigm. There was good evidence of temporal discrimination in these animals.
\end{abstract}

In a long history of avoidance conditioning studies spanning nearly 4 decades, many experimental situations have been employed which can be roughly classified into two categories. In one class of situations, the subjects are required to make a definite locomotive response to avoid, such as in the frequently used shuttlebox, runway, jump-out box (Maatsch, 1959), and jump-up-on-a-shelf (Baum, 1965) situations. In the other class of situations, subjects are required to make a response on some manipulandum, such as a lever or a wheel. Because of ease of automation, this latter type of situation is extremely convenient. Unfortunately, however, it is difficult to obtain stable avoidance behavior in the manipulandum situation, with both discriminated and nondiscriminated avoidance paradigms (D'Amato \& Schiff, 1964; Meyer, Cho, \& Wesemann, 1960; Myers, 1959; Weisman, 1962).

In recent years, especially in psychopharmacological and psychophysiological studies, there has been a strong tendency to use the nondiscriminated leverpress avoidance task, and the difficulty of obtaining a stable criterion response is a limitation that needs to be addressed. It seems to be conventional in some psychological and pharmacological laboratories to use only those animals in which a stable baseline criterion (avoidance) response was acquired within some number of sessions and to discard those that failed to do so. Under such circumstances, there is always the danger that the laws obtained apply only to those animals which acquired the avoidance response successfully.

The present experiment addressed this problem from both practical and theoretical considerations. From a practical point of view, it is important to find an avoidance conditioning task in which automation is as easy to apply as in the Skinner box and in which the avoidance response (hereafter referred to as $\mathrm{Ra}$ ) is acquired relatively easily. From a theoretical point of view, it is of interest to find out whether or not any operant can be efficiently avoidance-conditioned in a closed situation in which "Ra keeps Ss there"' (Bolles, 1971, p. 203) even after the response is made.

Riess and Farrar (1972), as well as other investigators (Grossen \& Bolles, 1968; Keehn, 1967; Rescorla \& LoLordo, 1965), successfully conditioned Sidman avoidance in a shuttlebox. In comparing this result with the frequent finding of poor Sidman avoidance in a Skinner-box type of situation, there are at least two factors in which the two situations differ. These are a difference in the response topography (running vs. leverpressing) and a difference in the change of the stimulus situation that occurs after responding ( $\mathrm{Ra}$ leads the subjects to the safety space vs. "Ra keeps Ss there"). In the present experiment, only the required response topography was changed, in order to see whether the difficulty of obtaining a stable leverpress avoidance could be ascribed to the nature of the required operant (leverpressing) or to the nature of the situation (absence of the safety space). In the present experiments, the required response was the change of the rat's posture from the sitting posture to the rearing posture or, in the case of Experiment 1, vice versa.

\section{EXPERIMENT 1}

The purpose of Experiment 1 was to investigate conditioning of the rearing and sitting responses using a discriminated avoidance conditioning paradigm. In order to escape or to avoid, rats had to interrupt light beams which ran at a certain height above the floor, or to let the beams pass if the rats were interrupting the beams at the time of CS or US onset. The height of the beams above the floor 
level was systematically varied in order to find an optimum height.

\section{Method}

Subjects. The subjects were 36 experimentally naive male albino rats of the Sprague-Dawley strain. Their mean body weight at the beginning of the experiment was $291 \mathrm{~g}$.

Apparatus. The apparatus was a shock box made of clear Plexiglas plates, except the back panel, which was of brown bakelite. The inside dimensions of the box were $20 \times 14.8 \times$ $30 \mathrm{~cm}$ (see Figure 1). The floor of the box consisted of copper rods $(\phi=3 \mathrm{~mm})$ spaced $13 \mathrm{~mm}$, center-to-center. Along and outside the three sidewalks of the box was a U-shaped arm, as shown in Figure 1, on which a light-source, a light-receiver, and small pieces of mirror were attached. An invisible light beam emitted from the light source was received by the receiver after several reflections from the mirrors, as shown in Figure 1. Thus the rat's upward movements of greater than the height of the beams at any floor position resulted in the interruption of a beam or beams. The height where the beams ran above the floor of the box was adjustable; in the present experiment, the heights were $10,15,20$, and $25 \mathrm{~cm}$, for four independent groups. Twenty-six centimeters directly above the ceiling of the box were 20- and 40-W electric bulbs, the former of which was constantly on during the experiment. When the subject interrupted the beams with its upward movement, the 40-W lamp came on, which served as a feedback stimulus, and this light was on as long as the beams were kept interrupted. The CS was a $1,000-\mathrm{Hz}$ tone presented through a loudspeaker $29 \mathrm{~cm}$ directly above the ceiling of the box. The intensity of the tone was $85 \mathrm{~dB}$, measured inside the box. The US was a constant current $0.8 \mathrm{~mA}$ ac scrambled grid shock.

All the time durations, presentations of the CS and US, and recordings of the responses were done automatically.

Procedure. The subjects were divided into four groups of nine each, approximately matched in body weight. They were designated as Groups 10,15,20, and 25, corresponding to the light beam height in centimeters. Except for beam height, all rats were treated in an identical manner.

Each subject was handled for $10 \mathrm{~min}$ before the first escapeavoidance training session began. Then the subject was put into the shock box and habituated to the box for $5 \mathrm{~min}$, after which the first trial began. If the subject did not make the appropriate response within $5 \mathrm{sec}$ after the CS onset, the US was delivered and both stimuli remained on until the subject made the required response. If a subject failed to respond within $10 \mathrm{sec}$ after the US onset, both stimuli were terminated by the experimenter.

Throughout the training sessions, the avoidance response was possible in two directions. When the rat was not interrupting the beams at the time of CS (or US) onset, it could avoid (or escape) by interrupting the beams by an upward movement. When the rat was interrupting the beams at the time of CS (or US) onset, it could avoid (or escape) by letting the beams pass by a downward movement.

The intertrial interval was variable, ranging from 10 to $40 \mathrm{sec}$ and averaging $25 \mathrm{sec}$. Sixty trials were run per session, and five sessions were run approximately $23 \mathrm{~h}$ apart.

\section{Results}

Figure 2 shows the mean number of $\mathrm{Ra}$ of the four groups, in blocks of 10 trials. The acquisition of $\mathrm{Ra}$ is evident only in Group 15, which shows withinsession improvement of performance on each day, followed by a remarkable overnight decrement. This group also shows a gradual increase in the number of $\mathrm{Ra}$ across sessions. The mean percentages of $\mathrm{Ra}$ on the final day of training were $10.6 \%, 72.4 \%, 23.5 \%$, and $24.3 \%$ for Groups $10,15,20$, and 25 , respec-

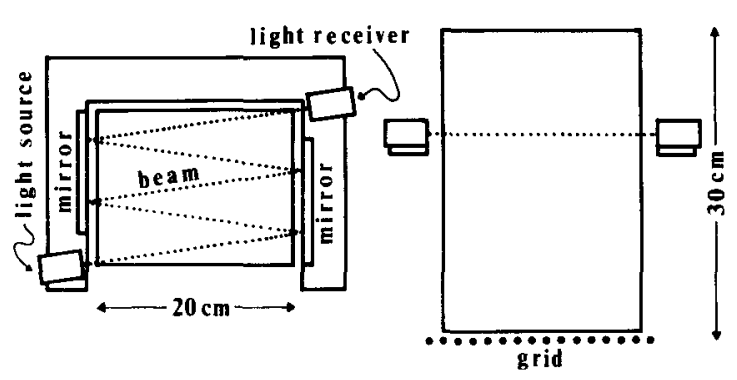

Figure 1. Floor plan (left) and side view (right) of the apparatus.

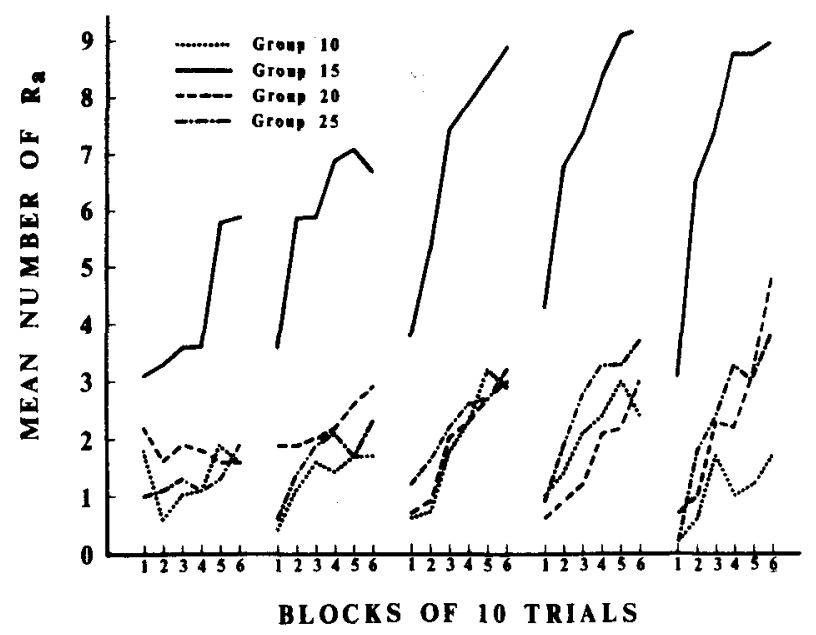

Figure 2. Mean numbers of Ra in the four groups as a function of training (Experiment 1).

tively, the difference among the groups being significant $[F(3,32)=15.17, p<.001]$. It is clear from the figure that the most effective avoidance conditioning was obtained in Group 15, the other three groups differing little in their performance.

The posture of the animals during the pre-CS period was recorded, and in Figure 3 the relative frequency of the up-posture is shown. The upposture was defined as a set of postures in which both forepaws were not touching the floor (except for facewashing, grooming, and scratching). The relative frequency of the up-posture subtracted from $100 \%$ is roughly the relative frequency of the down-posture, which was defined as postures in which either or both of the forepaws were touching the floor when the CS came on. Figure 3 shows that throughout training, the down-posture was dominant in Group 10. In the other three groups, the up-posture was relatively frequent in the early sessions, but only in Group 15 was a systematic increase of the up-posture curve observed. In Groups 20 and 25, the frequency of the up-posture gradually decreased, and the frequency of the down-posture increased. Lindquist's type I ANOVA, in which the between-factor was Groups and the within-factor Days, was performed on the data of Figure 3. The main effect of groups and the 


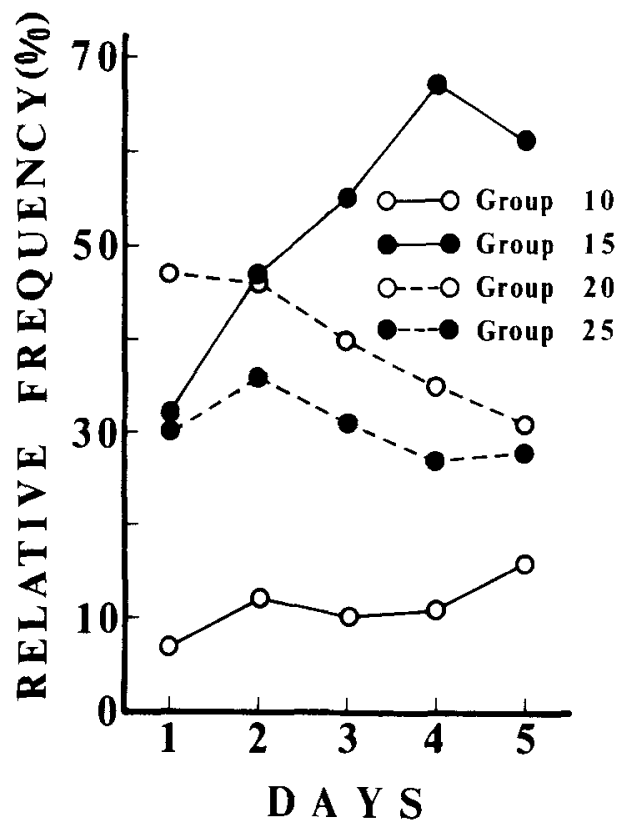

Figure 3. Frequency of pre-CS up-postures in the four groups as a function of training days (Experiment 1).

Groups by Days interaction were both significant $[F(3,32)=6.43, p<.005 ; F(12,128)=3.65$, $\mathrm{p}<.001$, respectively].

In Table 1 the results regarding the topography of . Ra are summarized for the upward and downward Ras; for the former, jumping and rearing Ras are indicated separately. It should be noted that the downward $\mathrm{Ra}$ is infrequent in all groups. It should also be noted that the frequency of the rearing $\mathrm{Ra}$ is remarkably high in Group 15. The percentages of rearing $R$ as in this group were $74.8,79.1,83.1,88.2$, and 88.8 from Day 1 to Day 5, an increase over days that was statistically significant $[F(4,32)=4.26$, $\mathrm{p}<.011$.

As to the response topography elicited by the US, the overall percentages of the jumping response were $57.2,89.8$, and 97.6 for Groups 15, 20, and 25, respectively. These percentages changed very little over the 5 days.

Table 1

The Number of Upward ( $\uparrow$ ) and Downward ( $\downarrow$ ) Avoidance Responses and the Number Accomplished by Jumping ( $J$ ) and Rearing (R) in the Four Groups of Experiment 1

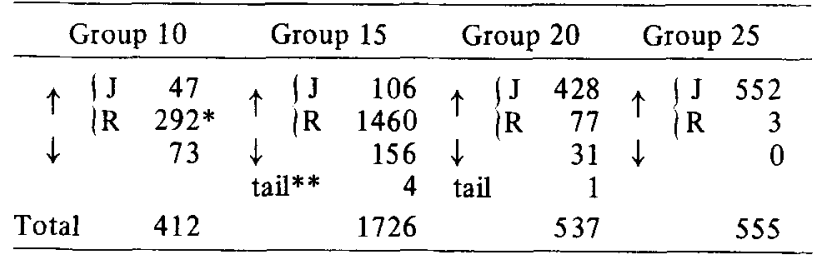

*Very frequently the subjects of this group cut the beams with their backs, a topography never observed in the other groups. **The beams were cut by tail movement.

\section{Discussion}

Experiment 1 showed that the rearing (sitting) $\mathrm{Ra}$ was successfully acquired when the amount of upward movement required was of a moderate degree, as in Group 15. This success contrasts with the early finding by D'Amato and Schiff (1964) that rats frequently failed to acquire discriminated leverpress avoidance even after thousands of trials. It should be noted that in both their experiment and in the present experiment no safety space was available to the subjects following $\mathrm{Ra}$. Although the difficulty in conditioning discriminated leverpress avoidance was later found to be attenuated when weak shock (0.16-0.25 mA) was used (D'Amato \& Fazzaro, 1966), the conditioning process was much slower in their case than in the case of Group 15 of the present experiment. It should also be pointed out that, in an experiment recently conducted in our laboratory with a beam height of $15 \mathrm{~cm}$, discriminated rearing avoidance conditioning was significantly better with $0.8-\mathrm{mA}$ than with $0.3-\mathrm{mA}$ shock, a fact quite contrary to what has been found in the leverpress situation.

It appears that the failure to develop avoidance responding in Group 10 should be discussed separately from the same failure in Groups 20 and 25 . The fact that Group 10 rats could not successfully acquire $\mathrm{Ra}$ is consistent with the experimental evidence which shows that an $\mathrm{Ra}$ involving a small movement is poorly acquired (Greene \& Peacock, 1965; Meyer, Cho, \& Wesemann, 1960; Turner \& Solomon, 1962). Greene and Peacock (1965), for example, found that rats were exceedingly poor at learning to be active when any movement of larger than 1 in. would effect avoidance. Turner and Solomon (1962) have also produced evidence that "reflexive" kinds of responses to shock may never be successfully turned into $\mathrm{Ra}$. An analysis of the response latencies of Group 10 revealed that $60.4 \%$ of the escape responses (Re) had latencies of less than $.06 \mathrm{sec}$, indicating the reflexiveness of $R e$ in this condition. The theoretical discussions regarding the difficulty of conditioning a small-movement response as $\mathrm{Ra}$ and/or conditioning $\mathrm{Ra}$ which is a replica of $\mathrm{Re}$ are not the immediate concern of the present experiment. It is of interest, however, to note the suggestion of Seligman and Johnston (1973) that "we might have to merely restrict the class of acquirable avoidance response to nonreflexive or 'intentional' responses"' (p. 100).

How then should the difference in the avoidance performance level of Group 15 from Groups 20 and 25 be explained? As shown in Table 1, the majority of Ras in Groups 20 and 25 were jumping, whereas in Group 15 the response was mainly rearing. The failure to obtain jumping avoidance is consistent with the findings by Bolles and Tuttle (1967) and Masterson and Whipple (1972) and inconsistent with 
the results obtained by Mowrer and Lamoreaux (1946). Theoretically, the present failure to condition a large-magnitude response contradicts the theory advanced by Meyer, Cho, and Wesemann (1960). They assumed that a response which effectively terminated the proprioceptive feedback stimuli (PFS) from the responses followed by shock can be conditioned efficiently. Typical responses which are followed by shock in an active avoidance situation are immobility or freezing responses, and the PFS from those responses should become aversive through conditioning. The feedback theory predicts that a large-magnitude active response, such as jumping, is exactly that which terminates this aversive PFS, and thus such a response should be conditioned more effectively than a smaller-magnitude response such as simple rearing. The present failure to obtain avoidance in Groups 20 and 25 and the success in obtaining $\mathrm{Ra}$ in Group 15 are quite contrary to what the proprioceptive feedback theory would predict.

Moreover, it should be noted that the frequency of the up-posture (see Figure 3) increased systematically in Group 15 as training progressed. This means that the pre-CS posture became more similar to $\mathrm{Ra}$ and that thus the $\mathrm{Ra}$ could not drastically change the pre-CS posture and the aversive PFS from it. According to our behavioral observations, the rats which most effectively acquired $\mathrm{Ra}$ came to wait for the CS with their heads just below the beams, and, with the presentation of the CS, they simply raised their heads an inch or so, thus effectively terminating the CS.

The present results seem more in line with D'Amato's assumption that the occurrence of the anticipatory escape response in sufficient numbers "puts $\mathrm{S}$ in a position to discriminate the avoidance contingency if one is in effect." (D'Amato, 1970, p. 372). The frequent occurrence of the up-posture, including rearing, which by its nature may be regarded as an anticipatory escape response, is evident in Group 15 (Figure 3). The fact that in Group 15 successful acquisition of $\mathrm{Ra}$ paralleled the frequent occurrence of the anticipatory rearing seems to fit D'Amato's hypothesis, provided that the up-posture is regarded as a suitable index of what D'Amato has called an anticipatory response.

However, the question of why the anticipatory escape posture of rearing developed in Group 15 and not in Groups 20 and 25 is a problem for the theory. One possible solution is that in Groups 20 and 25, $89.8 \%$ and $97.6 \%$ of the Res, respectively, were by jumping, whereas in Group 15, 27.6\% of the Res were by rearing, and there may have been a greater possibility of the rearing $\operatorname{Re}$ to be transferred to the anticipatory posture of rearing (see Figure 3 ) and in turn to the rearing $\mathrm{Ra}$ (see Table 1 ).
Presumably, in Group 15, the anticipatory rearing or up-posture was effective in terminating the shock promptly because of the rat's nearness of the beams, and hence was reinforced and maintained. In Groups 20 and 25, the anticipatory rearing posture was frequent during the first session (see Figure 3), but this did not lead to prompt termination of the shock, as in Group 15; it very frequently led to flinching before it finally ended with the jumping Re. Thus, the anticipatory rearing posture may not have been as effective in these groups as in Group 15. More precise ways to control the number of occurrences of anticipatory responses need to be developed.

\section{EXPERIMENT 2}

Experiment 2 was designed to investigate the possibility of conditioning the rearing response using a nondiscriminated or Sidman avoidance conditioning paradigm. The following modifications were made in this experiment: (1) The height at which the beams ran was fixed at $15 \mathrm{~cm}$ (the most effective height for conditioning of the rearing response in Experiment 1). (2) Only upward responding was effective as an $\mathrm{Ra}$.

\section{Method}

Subjects. The subjects were five experimentally naive male albino rats of the Sprague-Dawley strain, approximately 3 months of age at the beginning of the experiment.

Apparatus. The apparatus was the same as in Experiment 1, but the required minimum amount of rearing was $15 \mathrm{~cm}$.

Procedure. Immediately before the first session began, the subjects were handled for $10 \mathrm{~min}$. Each rat was then run for 28 sessions, I session per day, with a 24 -day vacation between Sessions 24 and 25. Each session started with an adaptation period of $5 \mathrm{~min}$, which was immediately followed by Sidman avoidance training lasting for $60 \mathrm{~min}$. The US was a constant current $0.3 \mathrm{sec}$ ac scrambled grid shock, which was $0.8 \mathrm{~mA}$ in intensity. The shockshock (S-S) interval was $5 \mathrm{sec}$ and the response-shock (R-S) interval was $20 \mathrm{sec}$, i.e., a beam-cutting response was effective in postponing the US for $20 \mathrm{sec}$. As in Experiment 1, interruption of the beams was always accompanied by the onset of the $40-\mathrm{W}$ feedback light.

\section{Results and Discussion}

The mean number of USs received and the mean number of responses over 28 sessions are presented in Figure 4. The following general tendencies occurred in all rats except Rat 3. (1) The number of responses was quite large in the early sessions and did not change a great deal throughout training. (2) The number of USs gradually decreased as training progressed. The number of USs received in Sessions 1 and 24 for each rat were 126-23, 178-28, 13-103, 245-35, and 146-15, for Rats 1, 2, 3, 4, and 5 , respectively. (3) There was a remarkable "vacation" effect (Manning, Jackson, \& McDonough, 1974); i.e., the number of USs decreased markedly 


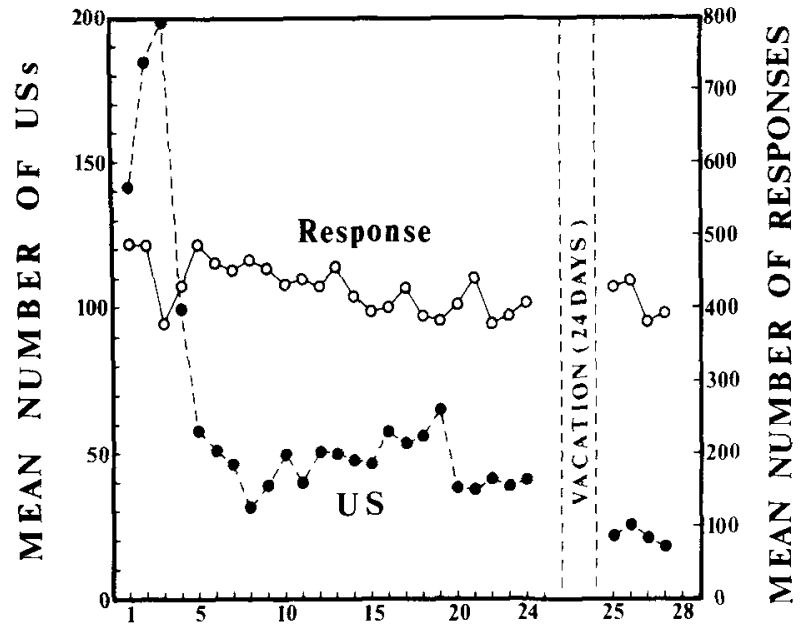

SESSIONS

Figure 4. The mean number of USs and the mean numbers of responses over 28 sessions (Experiment 2).

with the interpolation of 24 days during which no training took place. The number of USs in Sessions 24 and 25 were $23-11,28-11,103-59,35-23$, and $15-4$ in the same order of rats as described above. (4) There was a considerable overnight decrement in performance; i.e., at the beginning of each session, the subjects received a considerable number of USs which was followed by an improvement in performance within that session. (5) At the early stages of training, jumping responses were frequently observed which were replaced by a less effortful rearing response during the later stages of training. This shift in response topography was also observed within a session; at the beginning of a session, jumping was relatively more frequent than during the latter part of the session. Rat 3, unlike the rest of the rats, showed an exceptionally large number of responses from the very first session. This was in the form of a continuous vigorous jumping to the ceiling of the box, with the result that this rat received only 13 USs in Sessions 1. By Session 11, however, this continuous jumping tendency ceased, which suggests that early jumping may have had little operant meaning, and may simply have reflected emotional excitement aroused by the shocks. It seems likely that for this particular rat, true learning started somewhere around Sessions 12-14. By the end of training, Rat 3 showed evidence for a rearing avoidance response which was behaviorally similar to that produced by the other rats.

One may argue that the rearing avoidance response observed in the present study might not be an operant but simply reflect heightened level of arousal due to frequent shock administrations. There are two pieces of evidence against this possibility. The first is that, in an unpublished study by the present authors (Shimai, Yamazaki, Shishimi, \& Imada, Note 1) in which a discriminated avoidance paradigm was used, rats that received exactly the same amount of shock as the avoidance rats, but in which avoidance was made impossible by the use of a yoked design, developed marked freezing following an initial jumping tendency. The second line of evidence is that in the present experiment there was clear evidence of temporal discrimination, which is frequently observed in leverpress Sidman avoidance experiments with rats (e.g., Anger, 1963). Figure 5 shows the conditional probability curves for Rat 1 during selected sessions. The conditional probabilities were calculated following Anger's method (Anger, 1963). As Figure 5 shows, during the first session, the modal interresponse time (IRT) was very short, a result observed in all rats. But after extended training, evidence of temporal discrimination appeared, especially in Rats 1, 2, and 5. This is indicated in Figure 5 by the gradual shift of the peak of the IRT distribution toward the right. In Rats 3 and 4, there was some indication of temporal discrimination by the end of the training, but the evidence was less marked there than in Rats 1, 2, and 5.

Taken as a whole, the results of Experiment 2 show that the rearing avoidance response can be conditioned efficiently with a nondiscriminated avoidance paradigm. Application of the present technique to such areas as psychopharmacology and psychophysiology may prove fruitful.

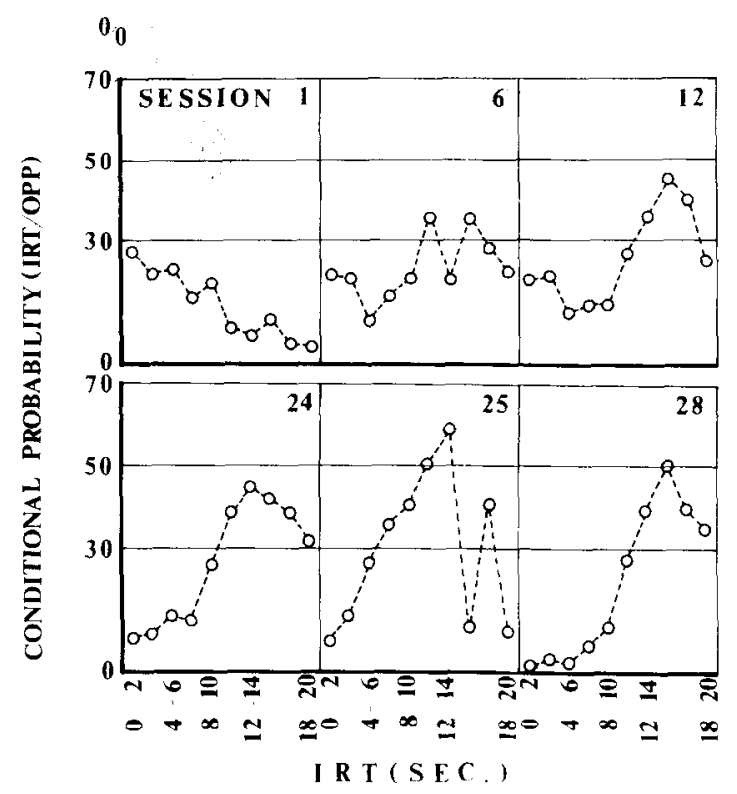

Figure 5. Conditional probability curves of Rat 1 for selected sessions (Experiment 2). 


\section{REFERENCENOTE}

1. Shimai, S., Yamazaki, N., Shishimi, A., \& Imada, H. An experimental study of rearing-sitting avoidance conditioning. Paper presented at the 34th Annual Meeting of the Japanese Society for Animal Psychology, 1974.

\section{REFERENCES}

ANGER, D. The role of temporal discriminations in the reinforcement of Sidman avoidance behavior. Joumal of the Experimental Analysis of Behavior, 1963, 6, 477-506.

BAUM, M. An automated apparatus for the avoidance training of rats. Psychological Reports, 1965, 16, 1205-1211.

Bolles, R. C. Species-specific defense reactions. In F. R. Brush (Ed.), Aversive conditioning and learning. New York: Academic Press, 1971.

Bolles, R. C., \& Tuttle, A. V. A failure to reinforce instrumental behavior by terminating a stimulus that had been paired with shock. Psychonomic Science, 1967, 9, 255-256.

D'Amato, M. R. Experimental psychology: Methodology, psychophysics and learning. New York: McGraw-Hill, 1970.

D'Amato, M. R., \& Fazzaro, J. Discriminated lever-press avoidance learning as a function of type and intensity of shock. Journal of Comparative and Physiological Psychology, 1966, 61, 313-315.

D'Aмato, M. R., \& Schiff, D. Long-term discriminated avoidance performance in the rat. Journal of Comparative and Physiological Psychology, 1964, 57, 123-126.

Greene, J. T., \& PeAcock, L. J. Response competition in conditioned avoidance. Psychonomic Science, 1965, 3, 125-126.

Grossen, N. E., \& Bolles, R. C. Effects of a classical conditioned "fear signal" and "safety signal" on nondiscriminated avoidance behavior. Psychonomic Science, 1968, 11, 321-322.

KEEHN, J. D. Running and bar pressing as avoidance responses. Psychological Reports, 1967, 20, 591-602.

MAATSCH, J. L. Learning and fixation after a single shock trial.
Journal of Comparative and Physiological Psychology, 1959, 52, 408-410.

Manning, F. J., JACKson, M. C., JR., \& McDonough, J. H., JR. A simple method of improving lever-press avoidance by rats. Bulletin of the Psychonomic Society, 1974, 4, 5-8.

Masterson, F. A., \& Whipple, M. C. The role of proprioceptive stimulus change in the rat's avoidance learning. Psychonomic Science, 1972, 27, 260-262.

Meyer, D. R., Cho, C., \& Wesemann, A. F. On problems of conditioning discriminated lever-press avoidance responses. Psychological Review, 1960, 67, 224-228.

Mowrer, O. H., \& Lamoreaux, R. R. Fear as an intervening variable in avoidance conditioning. Journal of Comparative Psychology, 1946, 39, 29-50.

MyERS, A. K. Avoidance learning as a function of several training conditions and strain differences in rats. Journal of Comparative and Physiological Psychology, 1959, 52, 381-386.

Rescorla, R. A., \& LoLordo, V. M. Inhibition of avoidance behavior. Journal of Comparative and Physiological Psychology, 1965, 59, 406-412.

RIEss, D., \& FARRAR, C. H. Unsignalled avoidance in a shuttlebox: A rapid acquisition, high-efficiency paradigm. Journal of the Experimental Analysis of Behavior, 1972, 18, 169-178.

Seligman, M. E. P., \& Johnston, J. C. A cognitive theory of avoidance learning. In F. J. McGuigan \& D. B. Lumdsen (Eds.), Contemporary approaches to conditioning and leaming. Washington, D.C: Winston, 1973.

TuRner, L. H., \& Solomon, R. L. Human traumatic avoidance learning: Theory and experiments on the operant-respondent distinction and failure to learn. Psychological Monographs, 1962, 76(40, Whole No. 559).

Weisman, A. Nondiscriminated avoidance behavior in a large sample of rats. Psychological Reports, 1962, 10, 591-600.

(Received for publication August 13, 1976; accepted April 11, 1977.) 